\title{
EIGHT-AND-A-HALF PROPOSITIONS TO STIMULATE FRUGAL INNOVATION IN PUBLIC SERVIGES
}

\author{
Jean Hartley \\ Open University Business School
}

\section{Introduction}

In this chapter I aim to distil some of the key ideas and practices that research has revealed can stimulate or support the processes and outcomes of innovation in public service organisations. Some of the propositions may be surprising to readers, given the conventional wisdom about innovation, which sometimes includes frankly wishful thinking. There has also been an over-reliance (still) on the private sector for the understanding of innovation, and more written about manufacturing than about service innovation.

I intend to set out how innovation can be fostered, in a way that recognises the distinctive features of public services (Osborne et al. 2013; Benington and Moore 2011) and that draws on but is not blinded by the private sector. My hope is that these propositions will act as provocations to policymakers, public managers and academic researchers, challenging current thinking and creating new ways to approach innovation, drawing on evidence and the latest research. The chapter originally consisted of 10 propositions, but following the 
global financial crisis, many public services have been cut, and this includes academic writing! However, hopefully I have been able to do 'more with less' in this chapter.

This is an opportune time to revisit the processes and practices of innovation, for at least two reasons. First, the cutbacks in public spending following the global financial crisis have led policymakers and public managers to think more closely about innovation - instead of 'salami-slicing' — as a way to cope (Kiefer et al. 2014).

Second, a new phenomenon of frugal innovation has been observed in emerging markets such as India (e.g. Immelt et al. 2009; Prahalad and Mashelkar 2010), and the concept is being picked up and applied to cash-strapped post-industrial economies. Frugal innovation provides a different way to go about innovation: instead of costly Research and Development (R\&D) laboratories and top-down strategies, innovation can also occur at the bottom of the corporate pyramid, and can be undertaken with the careful use of resources and the avoidance of waste. In public services, some innovation has always been of this type, created by employees close to where services are delivered. The concept of frugal innovation now perhaps gives this approach a greater respectability. The Oxford Dictionary defines frugal as 'simple and plain and costing little'. As we shall see, a newer approach to innovation means that frugal innovation involves borrowing and not just inventing, which entails an outward focus beyond the organisation.

These two trends in thinking about innovation mean that public services innovation has to operate effectively on very limited resources, given the financial context of public services around the world. One of the most obvious ways to stimulate frugal innovation is to reduce the costs of creating, developing and trialling innovations, and the propositions here will offer some opportunities in this respect.

Before presenting the propositions, it is worth addressing one myth about the public sector - that it is not very innovative. Innovation is something often seen as reserved for the private sector-this is an ill-founded view (Hartley et al. 2013). We are surrounded by innovations created by the public sector, not least the origins of the internet, but also a range of information technologies such as the Global Positioning System (GPS), the touchscreen and Siri, as noted by Mariana Mazzucato (2013). There are also many innovations in human services including social innovations, such as microcredit, or the use of iPads for pharmacists to check on the medicine-taking of elderly patients. We may wish for more innovation by public organisations, or that it is done in different ways, but there is already a great deal happening (Hartley et al. 2013; Osborne and Brown 2013). 
To set the scene, we need to define what is meant by innovation. First, innovation is more than ideas or invention - rather, it is about new ideas and new practices that are actually implemented (Bessant 2005). Second, innovation is not the same as change; it is a particular form of change. Many scholars argue that it is disruptive change, or 'step-change' (Lynn 1997). So innovation is different from continuous improvement, because it is not about gradually increasing efficiency and making things better - rather, it is about doing things differently. This may involve a different mindset, a different set of practices; something that is quite disruptive for the organisation. Third, innovation should not be conflated with improvement, or better performance, or success. It is quite possible to have very interesting innovations that, for whatever reason, are not successful at that particular time and place (or at all). Fourth, innovation is not necessarily an entirely new idea never seen before - it is innovative if it is new to the organisation or group adopting the innovation. Thus, innovation is about newness to the organisation - it doesn't matter that it is something that has already happened somewhere else.

In order to examine the propositions carefully, it will help to draw on three analytical phases of innovation: invention, implementation and diffusion. Invention relates to the processes of finding or creating the ideas that will be worked up into an innovation. It includes creativity and experimenting with new ways of doing things. Implementation is about turning an idea into an actual product or service. It might include piloting, trialling, and going larger scale in the organisation or partnership; so it is about embedding the innovation. Diffusion refers to the spreading of a particular innovation outwards across different organisations.

This is, admittedly, a simplified view of innovation, as there are many different models of the stages or phases (Hartley 2013). In addition, the phases may be more emergent than planned. Christian Bason (2010) describes innovation as more like a half-wound ball of yarn than a fixed set of phases. However, while simplified, the three phases are useful for the analysis in this chapter because they suggest different processes at different phases. Some of the propositions will relate to some phases and not others, or have different effects according to the phase. Having briefly outlined the characteristics of innovation, I now turn to consider the propositions. 


\section{Proposition 1: Market competition does not necessarily stimulate innovation}

Market competition can, but does not inevitably, stimulate innovation. Indeed, sometimes it can hamper innovation. This sounds a little counter-intuitive, especially in an era when there have been strong policy reforms designed to make public organisations more competitive and/or create quasi-markets, and therefore (so the logic goes) increase pressures to be more innovative.

The market competition linked to innovation argument has a long pedigree, going back to Joseph Schumpeter (1950) and echoed since then in economic arguments about 'creative destruction' - the idea that firms are under continual pressure to innovate or else they die. This notion has often been imported into public services with attempts to bring about or simulate market competition. But does market change really help to bring about innovation?

Analysis by Jean Hartley, Eva Sørensen and Jacob Torfing (2013) shows, from a review of the literature, that private sector markets can produce both too much and too little innovation (e.g. Teece 1992). Markets produce too much innovation in the sense that competition often encourages firms to innovate at the invention stage - they put a lot of effort into creativity and into protecting their innovation prototypes through patents and design rights. However, many firms deplete their resources at that stage and so are not able to capitalise on the benefits to be gained at the implementation stage. So, there is less innovation than one might expect. Markets also produce too little innovation where the level and scale of competition leads firms to believe that they will not be able to corral the benefits of the innovation to their own firm, but rather that other firms are going to snatch the benefits. This degree of competition reduces innovation. For the public sector, Richard M. Walker (2008) found that competition was associated with marketisation as a form of innovation but did not affect other aspects of innovation.

It is also known that market competition reduces the diffusion phase of innovation, which involves spreading good (or promising) practices, because it reduces or blocks the sharing of knowledge and ideas across competitor boundaries (Nelson and Winter 1977). I will argue later in this chapter that diffusion is a key element of innovation for public services. So, in increasing competition between public services, is there a risk of damaging the willingness to share and spread innovations?

From this first proposition comes the need to think carefully about the role of market competition or quasi-markets in public services. Market competition may increase innovation, or it may hamper it depending on the conditions- 
and this may also vary over time. There is a need for a more contingent view of markets in public services - when do they stimulate and when do they hamper innovation?

\section{Proposition 2: Bureaucracy can be both a help and a hindrance to innovation}

Whether an organisation is in the private, public or voluntary sector, bureaucracy can have contradictory effects (rather like competition but for different reasons). I mean 'bureaucracy' as a particular form of organising characterised by job descriptions, tasks, offices and division of labour (Weber 1947; du Gay 2000) rather than a pejorative term.

Research suggests that bureaucracy (whether in the private or public sector) generally makes it more difficult for employees to be creative and for organisations to foster the early stages of innovation, which require imagination, experimentation and risk (Thompson 1965; Damanpour 1991). Bureaucratic organisational processes exist to reduce uncertainty, and enhance predictability and efficiencies in mass production, stability and routine. So it is not really surprising that the more organisational processes and cultures are ordered, routinised and standardised, the harder it is to experiment with innovation in the invention stage. Research shows that the private sector can be just as bureaucratic as the public sector (Rainey and Chun 2005), so government institutions are not particularly afflicted in that sense. One of the key challenges for many organisations wanting to foster innovation is how to become ambidextrous (e.g. Levinthal and March 1993; Utterback 1996). This means being able to run business as usual — serving clients and citizens and so on - but also being able to foster creativity and innovation at the same time. There are different strategies to try to achieve this, not always successful because it is a tough ask. However, some organisations illustrate that it can be done, and there is a lot to learn from ambidextrous organisations.

So far, so conventional: bureaucracies make innovation more difficult. However, research also shows that bureaucracy can aid innovation (Hartley et al. 2013). This is perhaps surprising, but bureaucratic organisations sometimes find it easier to implement innovation (Hage and Aiken 1967; Zmud 1982). Although the invention stage is more difficult, once ideas have been trialled, developed and accepted, then bureaucracy helps in embedding innovations. For example, the processes of order and routinisation mean that new procedures and standards get written down, and line management can be used to help implement the changes. By contrast, less bureaucratic organisations can be creative at the trial stage, but find it harder to ensure that new procedures or practices are followed. 
Fariborz Damanpour and Marguerite Schneider (2006) found that size (which is often related to being bureaucratic) was helpful in all phases of innovation. Finally, there is some evidence that larger organisations are better at diffusing the innovations they have implemented, as was found in a study of UK local government (Rashman et al. 2005). Overall, the concepts of 'innovation' and 'bureaucracy' are not as inimical to each other as is sometimes supposed.

\section{Proposition 3: The key resource in organisations isn't primarily finance but human energy}

In a period of substantial fiscal constraint, discussion about change and innovation in public service organisations is often dominated by finance. As a result, innovation is discussed in one of two ways: as either the quick-fix technique to do more with less, or as an attractive but expensive luxury that cannot be undertaken for the time being because there are insufficient funds.

However, while the focus is on finance and budgets, it can be argued that the key resource is people. Emerging research suggests that the energy that they have as individuals, as groups, as teams, as departments, is important. Nurturing a positive climate for innovation can really help in the creation and development of new ideas and new practices, and in their implementation (West et al. 2003).

The NHS Institute of Innovation and Quality (Land et al. 2013) has been exploring five types of energy relevant to organisational performance:

- social energy (the energy that happens in teams, esprit de corps, energy created through working with others)

- spiritual energy (a sense of a higher purpose and direction that people have about the organisation; it is not defined as faith-based)

- psychological energy (courage, trust in other people, a sense of psychological safety in taking risk)

- physical energy (to do things and make things happen), and

- intellectual energy (curiosity, horizon scanning, strategic analysis, planning).

This is a promising approach to thinking about how organisations are less or more effective. Some of the types of energy have counterparts in existing organisational concepts (morale, commitment, trust), but the originality lies in thinking of the organisation in energy terms. Energy can spread or fizzle out. The metaphor has intuitive appeal in that any manager can recognise a team or department that has energy, buzz, initiative, proactivity, compared with one that is flat, demoralised, lacking in energy. This initial research deserves further attention. 
It is worth considering which of these energies are particularly present in our organisations, and which ones are much weaker or absent. The NHS study found considerable intellectual and physical energy (very bright people engaged in strategic planning and healthcare analysis; as well as people doing things, performing operations and caring for people). However, social, spiritual and psychological energy levels were much lower.

Neuroscience provides valuable metaphors for conceptualising human energy in organisations, and could provide an interesting research agenda (Butler and Senior 2007). Chemical and electrical energy are constantly flowing and moving between synapses in the neural system, continually creating new pathways and neural networks. The network is dynamic as it responds to stimuli. Transferring these ideas into an organisational or partnership context raises some interesting diagnostic questions. Where does the energy move around in organisations and partnerships? What are the conduits for it? Who are the people that act like synapses, helping to translate energy from one neuron to another?

This provides a very different picture of innovation to one derived from a static organisational chart. Energy concepts lie not far below the surface of some accounts of organisational change and innovation. Consider this statement about innovation:

A leader/entrepreneur is more effective if a bit of charisma is combined with a lot of good judgment, tolerance of ambiguity and a love of argument, passion, risks and action. Leave your door, and your mind, open (Lynn 2013, 41).

In the quotation, a number of words are about energy: charisma, argument, passion, action. Innovation is something that alters the status quo, and supplants or modifies existing ways of planning or providing public services. Arguably therefore, human energy is at the heart of the process.

\section{Proposition 4: Harvesting ideas and practices from others can save time and money}

The stereotype of innovation is that it starts with lots of people encouraged to be creative within the organisation, perhaps working in an R\&D department or policy unit, or perhaps in a workshop or 'sandpit' event. In other words, the assumption has been that invention happens within the organisation.

This was a dominant model of innovation in the private sector for a number of years, but interestingly that model is radically changing across all sectors. It is not always necessary to invent and create things from scratch, because a number 
of promising products and practices already exist somewhere and may be ripe for use in a different organisation or in a different context. This represents a shift from creating ideas to harvesting ideas as an approach to innovation.

Sometimes this can be 'recombinant' innovation - taking an idea, a product or a practice from somewhere else, and using it in a different way (Hargadon 2003). An illustration of this process comes from Great Ormond Street Hospital's use of ideas and practices from Formula 1 racing. Doctors were concerned about the transfer of sick children from surgery to intensive care, which involves a change of team and potential loss of key information in the transfer. Watching Formula 1 on television one day, some doctors were struck that a pit stop represented an important concept that could be modified and applied in the hospital. The transferable concepts were: a team-based approach, with each team member having a clear and specific role; the clear communication of the current state of the car through a set procedure; rehearsal of the pit stop so that everyone is clear about the tasks and has had practice in what to do; and, having one person in charge who makes the decision about whether the car is ready and safe to go back out on the track. As a team, they used these basic practices, modifying and adapting them for the different context and task. This is frugal innovation because the team with the need for innovation harvested ideas from elsewhere, and it was not a costly invention procedure. There are many opportunities to use ideas from different (or similar) contexts, with careful thought about how to apply or adapt those ideas in a different setting.

Another approach to harvesting ideas comes from open innovation (Chesbrough 2003). This is innovation that draws on the ideas and suggestions of users, clients, members of the public, and citizens. Some of these groups are interested and knowledgeable about public services. They may be experts in particular public services, either as users or as professionals who come into contact with that service. For example, children are helping to design hospital environments to make them child-friendly, and former drug addicts are helping to design and develop addiction services in Denmark. Dennis Hilgers and Christoph Ihl (2010) call this 'citizensourcing' (the public counterpart to crowdsourcing), and argue that it is an important source of ideas and practices for public organisations. It is different from public consultation (where a course of action has often already been decided). However, unlike open innovation in the private sector - where a firm can harvest ideas from anyone- public service organisations need to carefully think through who contributes and on what basis so that certain groups in society are not disadvantaged through the innovation process.

Harvesting ideas rather than (or as well as) inventing them in-house is a radically different model of innovation. It requires looking outwards, not inwards, because the innovation may be a novel application of a product or practice in 
an entirely different setting. It still depends on a positive innovation climateenergy and curiosity to engage with ideas from the external world beyond the service or organisation.

\section{Proposition 5: Diffusion of innovation is the public sector's secret weapon}

Not enough attention is paid to diffusion as a phase of innovation in public service organisations. This may occur for a number of reasons. The public services innovation literature has, until quite recently, been over-reliant on the understanding of innovation derived from the private sector (Hartley 2013), in part because of the assumption that innovation comes through competition, but also due to the lack of research from public management researchers. In the private sector, diffusion is often the last thing that firms wish to engage in, especially where there is stiff market competition enabling value capture by other firms. Consequently, the literature on diffusion is still somewhat sparse compared with the other phases of innovation.

Yet, for public services, diffusion can be a very effective way of undertaking innovation. It reduces the costs of invention-instead of reinventing the wheel, the existing wheel can be used, avoiding the development costs and mistakes made by another organisation. Diffusion reduces the operational and political risks of the innovation, because it has been tried and tested in another context. Snags have hopefully been smoothed out, improvements in design or operation can be made, and the political risk of working with an unknown product or service reduced. The argument that risk is a problem for public service innovation is thus mitigated by drawing on others' experience. Furthermore, in public services, those who have innovated are sometimes keen to share their experience (Rashman et al. 2005). Finally, many public organisations have a moral imperative to share their innovations, because society needs innovation to be spread beyond the initial innovator. There is little value in having an effective innovation in (for example) cancer care if it is limited to a single hospital. Despite these arguments about the value of innovation, how much do public managers allocate in the way of resources and organisational procedures towards sharing good and promising practices, compared with inventing and implementing innovation?

There are some important examples of diffusion, for example in health and in local government. Diffusion is not simply replication or 'copy and paste' from the innovator. In a large study of sharing innovation in UK local government (Hartley and Benington 2006; Rashman et al. 2005), diffusion was found to be widespread but also to involve critical processes of adaptation to local context 
and conditions. The UK's Beacon Scheme was a national program operating for over a decade in the early twenty-first century. It aimed to celebrate high performance and innovation, and spread good practice from the 'innovators' to the 'learner' organisations. Among the learner organisations in 2004 that had used ideas from the innovator, there were varying patterns in the way that diffusion was implemented. Sixty-three per cent reported that they had adapted the idea from the innovator. This shows that adjustment takes place as the innovation moves from one organisation to another. Adaptation happened more than adoption. In addition, 29 per cent reported that they accelerated an idea which they already had. From interviews, it was possible to ascertain that this gave the learner greater confidence in using the innovation, and also that it reduced risk and built political (both small and big ' $p$ ') support. Finally, only a small percentage -8 per cent - said they based their change closely on the innovator.

Diffusion does not need to cost much. The innovations are already there, being used, and with some known properties. Why is diffusion not more widespread? And why is there not more research on diffusion as a critical stage of innovation for public services?

\section{Proposition 6: Knowledge creation and learning is central to innovation}

It is easy to get fascinated by innovative technologies - the information and communications technology (ICT), the new equipment, and so on-and treat them as though they are the innovation. But this is rarely the case; the innovation is likely to be not just the technology but also the practicalities of making it work - and that requires new knowledge being created and transferred between human beings (Nonaka 1994; Hargadon 2003). Learning is partly undertaken by individuals in relation to their own job, but it also involves learning in teams and sections, and indeed learning across the organisation and between organisations (Rashman et al. 2009). Knowledge and learning may be particularly critical for service innovations, where the key elements of the innovation consist of the new or substantially altered relationships in service creation (whether those relationships are between service user and professional, between professionals, or between managers and subcontractors).

Learning may involve new concepts and procedures, and also involve working out how the innovation fits with existing practices and procedures (Behn 2008). Adjustments may be necessary as plans are altered after 'teething problems', or there is recognition of fine-tuning. Sometimes an innovation will create unanticipated problems (and benefits) in areas not directly connected with the 
innovation (Hartley 2005). So observation, reflection, discussion and learning are advisable as the innovation develops from invention to implementation to diffusion. It is generally not possible to innovate without people (whether managers, staff, clients, or politicians) having to learn new ways of doing things, making mistakes, giving up particular ways of doing things, and adopting new ways. This is essential, but often goes unremarked.

Innovation is rarely a primrose path - it is full of all sorts of obstacles, cul-de-sacs and frustrations, and people need time to learn from that, and time to put this learning into practice. Learners generally want to learn as much about the frustrations, barriers and problems in innovation as they do about the successes (Rashman et al. 2005).

\section{Proposition 7: Public innovation can benefit from the contributions of politicians}

This might sound like an obvious proposition, but whether explicitly or under their breath, some managers tend to feel that they could innovate much better without politicians. In addition, relatively few academics have studied the role of politicians in innovation. This may be a legacy of over-reliance on private sector thinking about innovation.

Some research shows that elected politicians, whether national, state/devolved or local, are important in all sorts of ways (Rashman and Hartley 2002; Hartley and Rashman 2007). They can build public support for innovation before it occurs, help to deal with sceptics, listen to the views of doubters and bring them round to support, and mobilise various stakeholders, including collaborators across sectors and services. They can provide the right climate to enable managers and staff to experiment, and they can challenge technical thinking, combining it with political nous. They can help unblock problems and build coalitions to support the innovation. In short, they can be a key part of the leadership of innovation (Hartley 2013). Not all politicians play these roles or play them effectively, but they are active in case studies of significant innovations in public services. 


\section{Proposition 8: 'Innovation and improvement' is not a single concept}

'Innovation and improvement' is often used as a single policy phrase, as though innovation were so naturally and inevitably beneficial that it always leads to improvements (e.g. in service scope or quality, in efficiency, in value for money). However, not all innovations lead to improvement, and not all improvements require innovation.

An innovation, by virtue of its newness to the organisation or partnership, inevitably carries some risk of failure or partial failure. Joe Tidd, John Bessant and Keith Pavitt (2001) estimate that in the private sector approximately a third of innovations fail, or are inappropriate for the particular time or context. In the public sector the percentage may well be higher, because there is a more critical and transparent environment within which innovations occur.

Some organisations in any sector suffer from having too much innovation. Michael Moran (2003) argues that the UK state is characterised by 'hyperinnovation', with too many innovations being initiated. He questions the extent to which this has had a beneficial impact. From a different perspective, Marianne Jennings (2006) argues that hyper-innovation within an organisation can be a sign of ethical collapse, where managers use innovation as an argument to take unjustified ethical risk.

Conversely, not all improvement involves innovation. Improvement can occur through continuous improvement methodologies, which are based on doing things better, rather than innovation, which is based on doing things differently (Hartley 2011). These different approaches to improvement have different implications for managing change, leadership, motivating staff and the extent to which one might anticipate the outcomes being planned or partly emergent. Working out what magnitude and kind of change is desirable, in what context, and over what timescale, may help to shape whether an organisation should embark on continuous improvement or innovation.

\section{Buy eight, get one free: Building a robust evidence base}

The final (half) proposition concerns the creation of a robust evidence base about public innovation. I have noted several times in this chapter that policymakers, public managers and academics are still overly reliant on concepts, frameworks 
and theories about innovation derived from the private sector. It is important to construct and use a systematic evidence base about what works for innovation in public services, and for collaborative innovation across sectors and services.

There is unlikely to be 'one best way' to innovate - it depends on the context, the political climate, the purpose of the innovation. But what works, for whom, in what circumstances, and why still needs addressing in detail. There is a need to learn from failures as well as successes, rather than quietly sidelining innovations that do not work. This is not easy of course, given the glare of the media, particularly in relation to the more spectacular innovation failures in the public sector. There can also be a 'blame game' in politicised environments such as public services. However, public managers and others can gain from understanding what went wrong, or what failed to thrive in particular contexts, and use that to craft modified or alternative innovations. It is valuable to monitor and evaluate both successful and unsuccessful innovation initiatives, across all phases, including implementation and diffusion - not just the early buzzy invention phase. Bringing together learning from academics, policymakers and practitioners will create rich data about innovation for public service organisations, and build better understanding of innovation for the future.

\section{Conclusions}

I have presented eight-and-a-half propositions about innovation to stimulate debate, reflection and action. These derive from research findings, and create a picture of implications for action that are different from conventional thinking about innovation. For too long, innovation for governance and public services has been in the shadow of concepts and research derived from the private sector, and often a manufacturing perspective has been prioritised over a service perspective. There is a lot to learn from aspects of private sector innovation processes and outcomes, but like innovation itself, diffusion of ideas from one sector to another needs adaptation not adoption. There is a need to think carefully about the specific elements of the public innovation context, processes, stakeholders and outcomes, so that approaches to innovation are appropriate to context and purpose. So, quasi-markets or market competition may be problematic as well as helpful, just as bureaucracy can help as well as hinder. In public innovation, diffusion takes a much more prominent place than has previously been recognised.

I hope that taking account of these eight-and-a-half propositions will help public organisations, either alone or in partnership with the private and voluntary sectors, to create frugal innovation. It is the right time to create and deploy a more informed understanding of public innovation, given the current interest 
in innovation as a means to avoid 'salami-slicing' public services, and given new developments in frugal innovation. I do hope these propositions have provoked the readers of this chapter.

\section{Acknowledgements}

Thanks to John Benington for alerting me to the idea of human energy, and to Richard Blundel for reading an earlier draft of this chapter. An earlier version of this chapter was published as 'New development: Eight and a half propositions to stimulate frugal innovation', Public Money and Management (May 2014): 227-32.

\section{References}

Bason, Christian. 2010. Leading Public Sector Innovation: Co-Creating for a Better Society. Bristol: Policy Press.

Behn, Robert. 2008. 'The adoption of innovation: Learning to adapt tacit knowledge.' In Innovations in Government: Research, Recognition and Replication, ed. Sandford Borins. Washington, DC: Brookings, 138-58.

Benington, John and Mark H. Moore. 2011. Public Value: Theory and Practice. Basingstoke: Macmillan.

Bessant, John. 2005. 'Enabling continuous and discontinuous innovation: Learning from the private sector.' Public Money and Management 25: 35-42.

Butler, Michael and Carl Senior. 2007. 'Research possibilities for organizational cognitive neuroscience.' Annals of the New York Academy of Sciences 1118: ix-xii, 1-211. Online: onlinelibrary.wiley.com/doi/10.1111/nyas.2007.1118. issue-1/issuetoc (accessed 13 May 2015).

Chesbrough, Henry. 2003. Open Innovation. Boston: Harvard Business School Press.

Damanpour, Fariborz. 1991. 'Organizational innovation: A meta-analysis of effects of determinants and moderators.' Academy of Management Journal 34(3): 555-90.

Damanpour, Fariborz and Marguerite Schneider. 2006. 'Phases of the adoption of innovation in organizations: Effects of environment, organization and top managers.' British Journal of Management 17: 215-36.

du Gay, Paul. 2000. In Praise of Bureaucracy. London: Sage. 
Hage, Jerald and Michael Aiken. 1967. 'Program change and organizational properties.' American Journal of Sociology 72(2): 503-19.

Hargadon, Andrew. 2003. How Breakthroughs Happen: The Surprising Truth about how Companies Innovate. Boston: Harvard Business School Press.

Hartley, Jean. 2005. 'Innovation in governance and public services: Past and present.' Public Money and Management 25 (January): 27-34.

Hartley, Jean. 2011. 'Public value through innovation and improvement.' In Public Value: Theory and Practice, ed. John Benington and Mark H. Moore. Basingstoke: Palgrave, 171-84.

Hartley, Jean. 2013. 'Public and private features of innovation.' In Sage Handbook of Innovation in Public Services, ed. Stephen P. Osborne and Louise Brown. London: Sage, 44-59.

Hartley, Jean and John Benington. 2006. 'Copy and paste, or graft and transplant? Knowledge sharing through inter-organizational networks.' Public Money and Management 26(2): 101-08.

Hartley, Jean and Lyndsay Rashman. 2007. 'How is knowledge transferred between organizations involved in change?' In Managing Change in the Public Services, ed. Mike Wallace, Michael Fertig and Eugene Schneller. Oxford: Blackwell, 173-92.

Hartley, Jean, Eva Sørensen and Jacob Torfing. 2013. 'Collaborative innovation: A viable alternative to market competition and organizational entrepreneurship.' Public Administration Review 73(6): 821-30.

Hilgers, Dennis and Christoph Ihl. 2010. 'Citizensourcing: Applying the concept of open innovation to the public sector.' International Journal of Public Participation 4: 67-88.

Immelt, Jeffrey R., Vijay Govindarajan and Chris Trimble. 2009. 'How GE is disrupting itself.' Harvard Business Review (October): 56-65.

Jennings, Marianne. 2006. The Seven Signs of Ethical Collapse. New York: St Martin's Press.

Kiefer, Tina, Jean Hartley, Neil Conway and Rob B. Briner. 2014. 'Doing more with less? Employee reactions to psychological contract breach via target similarity or spillover during public sector organizational change.' British Journal of Management 25(4): 737-54.

Kelman, Steven. 2005. Unleashing Change. Washington, DC: Brookings. 
Land, Martin, Nick Hex and Chris Bartlett. 2013. Building and Aligning Energy for Change. London: National Health Service.

Levinthal, Daniel A. and James G. March. 1993. 'The myopia of learning.' Strategic Management Journal 14 (Winter): 95-112.

Lynn, Laurence E. 1997. 'Innovation and the public interest: Insights from the private sector.' In Innovation in American Government, ed. Alan Altchuler and Robert Behn. Washington, DC: Brookings Institution, 84-103.

Lynn, Laurence E. 2013. 'Innovation and reform in public administration: One subject or two?' In Handbook of Innovation in Public Services, ed. Stephen P. Osborne and Louise Brown. Cheltenham: Edward Elgar, 29-43.

Mazzucato, Mariana. 2013. The Entrepreneurial State. London: Anthem Press.

Moran, Michael. 2003. The British Regulatory State: High Modernism and Hyper-innovation, Oxford: Oxford University Press.

Nelson, Richard R. and Sidney G. Winter. 1977. 'In search of a useful theory of innovation.' Research Policy 6: 36-76.

Nonaka, Ikujiro. 1994. 'A dynamic theory of organizational knowledge creation.' Organization Science 5: 14-37.

Osborne, Stephen P. and Louise Brown. 2013. Handbook of Innovation in Public Services. London: Sage.

Osborne Stephen P., Zoe Radnor and Greta Nasi. 2013. 'A new theory for public service management? Toward a (public) service-dominant approach.' The American Review of Public Administration 43(2): 135-58.

Prahalad, C.K. and R.A. Mashelkar. 2010. 'Innovation's holy grail.' Harvard Business Review 88(7/8): 132-41.

Rainey, Hal G. and Young Han Chun. 2005. 'Public and private management compared.' In The Oxford Handbook of Public Management, ed. Ewan Ferlie, Laurence E. Lynn and Christopher Pollitt. Oxford: Oxford University Press, 72-102.

Rashman, Lyndsay and Jean Hartley. 2002. 'Leading and learning? Knowledge transfer in the Beacon Council Scheme.' Public Administration 80: 523-42.

Rashman, Lydnsay, Erin Withers and Jean Hartley. 2009. 'Organizational learning and knowledge in public service organizations: A systematic review of the literature.' International Journal of Management Reviews 10(3): 463-94. 
Rashman, Lyndsay, James Downe and Jean Hartley. 2005. 'Knowledge creation and transfer in the Beacon Scheme: Improving services through sharing good practice.' Local Government Studies 31(5): 683-700.

Schumpeter, Joseph. 1950. Capitalism, Socialism and Democracy. New York: Harper and Row.

Sørensen, Eva and Jacob Torfing. 2011. 'Enhancing collaborative innovation in the public sector.' Administration and Society 43(8): 842-68.

Teece, David J. 1992. 'Competition, cooperation and innovation: Organizational arrangements for regimes of rapid technological progress.' Journal of Economic Behavior and Organization 18(1): 1-25.

Thompson, Victor. 1965. 'Bureaucracy and innovation.' Administrative Science Quarterly 10(1): 1-20.

Tidd, Joe, John Bessant and Keith Pavitt. 2001. Managing Innovation. 2nd edn. Chichester: Wiley.

Utterback, James M. 1996. Mastering the Dynamics of Innovation. Cambridge, MA: Harvard Business School Press.

Walker, Richard M. 2008. 'An empirical evaluation of innovation types and organizational and environmental characteristics: towards a configuration framework.' Journal of Public Administration Research and Theory 18: 591-615.

Weber, Max. 1947. The Theory of Social and Economic Organization. Trans. A.M. Henderson and Talcott Parsons. London: Collier Macmillan.

West, Michael, Carol S. Borrill, Jeremy F. Dawson, Felix Brodbeck, David A. Shapiro and Robert Haward. 2003. 'Leadership clarity and team innovation in health care.' Leadership Quarterly 14: 393-410.

Wilson, James. 1989. Bureaucracy: What Government Agencies Do and Why They Do It. New York: Basic Books.

Zmud, Robert W. 1982. 'Diffusion of modern software practices: influence of centralization and formalization.' Management Science 28: 1421-31. 
This text is taken from Managing Under Austerity, Delivering Under Pressure, edited by John Wanna, Hsu-Ann Lee and Sophie Yates, published 2015 by ANU Press, The Australian National University, Canberra, Australia. 